\title{
A Review on Strengthening and Repair of RC Column by Jacketing.
}

\author{
Uday Dongre1, Dr. Kuldeep R. Dabhekar², Dr. Isha P. Khedikar³ \\ ${ }^{1} \mathrm{M}$-Tech. Scholar, ${ }^{2,3}$ Assistant Professor, \\ Department of Civil Engineering, G.H. Raisoni college of Engineering, Nagpur, Maharashtra, India
}

\begin{abstract}
The research aims to investigated the efficiency of repairs of the damaged concrete column using the concrete jacketing. Strengthen what's more, restoration by the reinforce concrete jacketing of the column is assessed, consider of the diverse useful aspect anchor and slab cross of the add longitudinal reinforced, interface surface readiness separating of widow stirrup transitory shoring of the structural and the addition of news to the concrete. Late research the topic and the main recommendation to accomplish great $\mathrm{RC}$ jacketing are introduced. Also, factors such as corrosions of the rebar or aging may be deteriorated or then again corrupt to the limit of the reinforce concrete section, thereby necessary prompt strength to either extends or ensured it designs life isn't constrained's. As in the instances of RC basic, segments are exposed to the garbs and ceaseless stacking with the increments in the no. of story and may prompt the incomplete relinquishment or plane aggregates disappointment of the sections. RC segments even before its help period is over immediately consideration is required in and the harmed piece of fortified cement is fixed by Greek and Latin made strengthened cement jacketing. The range of observation of these papers is limited to jacketing techniques for making strength warm feeling, desire fixing both typical and high strengths RC sections. The paper moreover takes to be the same possible unused quality operation of making observations openings, nothing in between, and outlines the future direction of operation of making observations into the making stronger and put right of RC columns.
\end{abstract}

Keywords : Strengthened Concrete columns, Reinforcement, Dowels rebar, Shear Connectors and RC Jacketing.

\section{INTRODUCTION}

The get-well and making stronger of damaged or deficient reinforced $(\mathrm{RC})$ structures have the possible unused quality to put back to earlier position warm feeling, desire give greater value to the to do with structure operation to a level needed by current design codes. Seismic retrofitting and the strengthen of RC column has been popular zone of the research for decades. This is primarily considering in a towers tower frame system or an underpass the imposed seismic energy demand is prodigal by the ostracism of the columns thereby resulting in slight to severely damaged pending on the severity of the earthquake, and for this reason the need for get in good condition again comes out of to make certain the smooth postearthquake get loss back in law of the building. The get in good condition again and get-well of the currently in existence structure are Major building operations. Strengthen concrete (RC) is to utilized broadly as structure material in an enormous bit of the earth. Structure made with these materials frequently endure harm due to over-burdening cataclysmic events eg quake and inflowing fire ecological impacts (eg. erosion), or changes in towers use outperforming arriving at their planned structure 
life. These harms may legitimization the auxiliary components to goof to meet the useful prerequisites inside their planned assistance life. If legitimate sustentation isn't paid in such manner, structures could great to siphon their plan burden, and catastrophes could happen. Reinforcing techniques rely upon the kind of structure and loadings. As to oppressed essentially to very still sums, expanding flexural and pivotal procedure of compelling together force is generally significant. Improving sections pliability and re-orchestrating segments firmness likewise be accomplished with fortifying strategies. Retrofitting should be possible in two diverse manners, rely upon the position and the degree of harm in basic part:

- Global Retrofitting

- Local Retrofitting

Columns one of the most not worthy structure individuals who move the whole burden to the establishment. The conduct of sections in tall structures is significant since segments missing the mark concerning one's expectations lead to the expansion of to do with structure missing the mark regarding one's expectations and can result in an allout structure out of nowhere give way. The substitution of the harmed auxiliary components is troublesome and may make a high hazard to the general basic respectability. Fixing an RC part might be shaped as an endeavor to return to prior position the unprecedented, noted force and firmness of a harmed or got terrible RC part. Distributed on experience workspace on the put right of $\mathrm{RC}$ segments, where an intriguing note between face paint gets in great condition again and to do with structure get in great condition again is introduced. The Authors give thought to making skin more beautiful get in good condition again if the power loss is lower than $10 \%$ and to do with structure get in good condition again if the power drop is above that value. The Authors state that the amount of room of the repaired column were discovered to be $15-20 \%$ less than the first form amount of room, and the stiffness value were $50-90 \%$ of the uncommon, noted value.

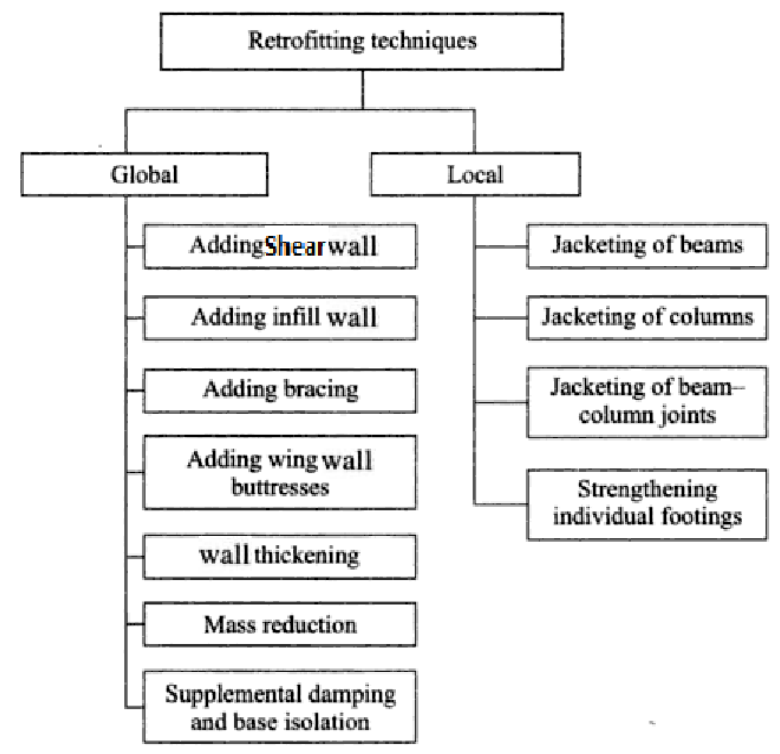

Figure 1. Flow Chart
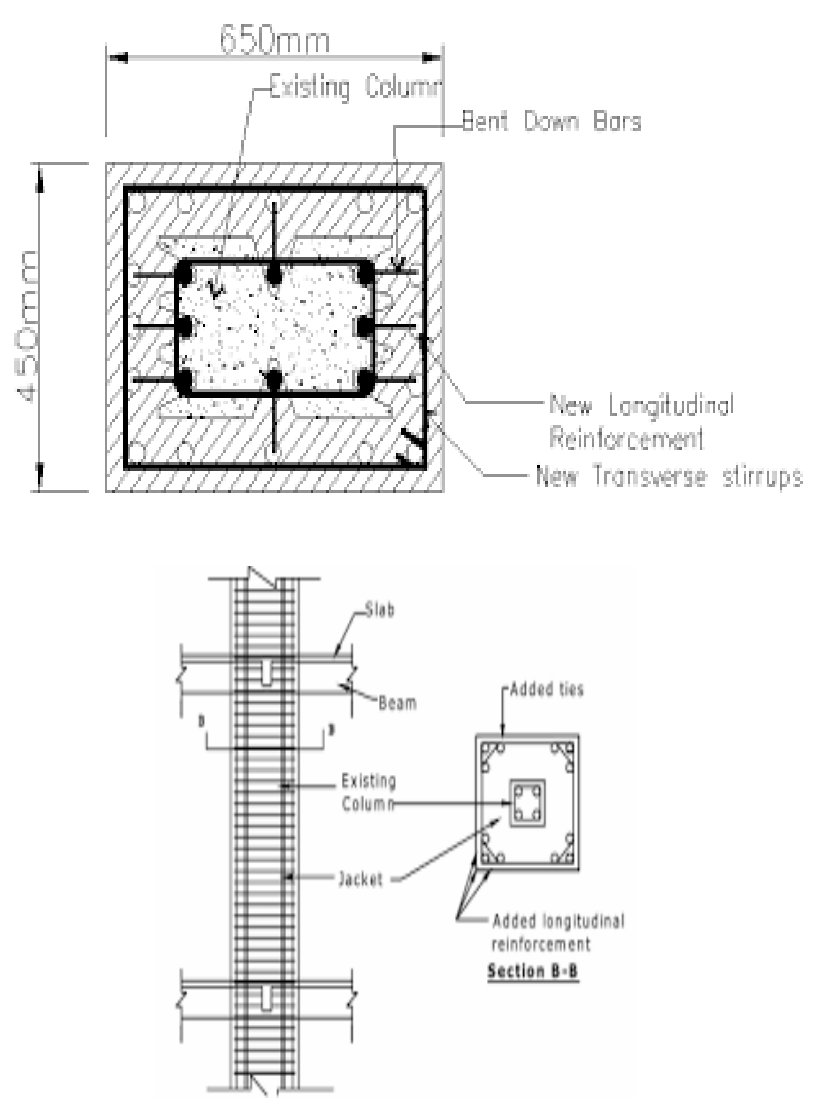

Figure 2. RC Jacketing for Concrete Column. 


\section{LITERATURE REVIEW}

Vijayakumar Amulya \& A. Dattatreya Kumar (1), In this paper, Strengthen of existing reinforced Column in old structures is turning into a note worthy issue during repair and supports. Economical reasonable materials such as Steel angle section are used for retrofitting a reinforced concrete of the Column under loading is observation. Installation of these angle sections is very easy and skilled labour is not required. The simulated model of these column were generation in finite element based software ANSYS and the behavior of these column were observed under same loadings and compare. The result of both experimental analysis and software analysis were also compared.

N. Lakshmanan, K. Muthumani \& T.S. Krishnamoorthy (2), Pre-disaster prepared strategies lead to the repair/retrofitting of reinforced touchable structure for ensure satisfactory performance during earthquakes. The repair can be lead to be increase stiffness, strengthen, and failure deformation. There is a needs to quantify the performance of the structure without a repair has to be carry out. The study have revealed that repair and retrofitting of structural elements with inherent. Beam-column joint which had largest detailing through the inclusions of corner bar perform better. When these were strengthen with CFRP, there was a significant resurgence in loadcarrying topics without loss of the failure deformation. detailing deficiencies would require greater superintendency and attention.

Prathamesh Dingorkar and Ayush Srivastava (3), Structure get dilapidateds with time for which repair are not feasible. Some structures cannot be kept sealed for longer reviviscence required for reconstruction. Retrofitting is an efficient method that can be unexplored to gainsay all these defiances. This vendible appends a comparative study of the percentages increase in strength without raise $\mathrm{RC}$ jacketing and FRP wrapping. Percentages increase in strength unzip without the RC jacketing and FRP wrapping is unswayable and compared. This study is the fruitful to gauges the suitability of the retrofitting method for weakened structure member. The study will be handy to help the structural engineer to decide which method of the retrofitting should be unexplored to reap the required increase in the strength.

Chetan Yalburgimath, Akash Rathod \& S Bhavanishankar (4), The using of CFRP fabrics whenever need, taking into consideration the zone of the CFRP fabric, rigid, and stiffness does result an increase of the strength of beams and provides spare load delivering capacity. A unconfined deal of the research is current stuff conducting concerning the used of the fiber-reinforced polymer fabric wraps, laminates, and sheets in the repairs and strengthening of reinforced touchable members. Fiber-reinforced polymer using is a very constructives way to repairs and strengthen structure that have will structural weaks over their life span. FRP is a repair system provided an economical viable volitional to traditional repairs system and material.

Tabish Rasool Sheikh, Mohd Kashif Khan \& Tabish Izhar (5), A thorough writing audit of the stir cleaned up in the past was concentrated to get the biggest thought of the key issues pertinent to the fortifying of RC sections with traditional fortified touchable jacketing. Besides, in contrast to another strategy, the current examination to have uncovered that the oldstyle RC jacketing leads to a uniform conveyance increment in quality and firmness of segments and, by and large, plane permits the structure to siphon the substantial seismic burdens. In wings of the first post is also improved. With the expanded interest for fixes and restoration in the field of auxiliary designing, 
Traditional RC jacketing will extend to develop as an affordable and durable retrofitting method.

Saim Raza , Muhammad K. I. Khan \& Scott J. Menegon (6), Weakening in the subjects of fortified touchable (RC) foundation may result from relinquishment supported during lattermost stacking situations, for example, seismic tremors. Additionally, factors, for example, the erosion of rebars or whitehaired may fall apart or depose the subjects of a RC segment, along these lines requiring firsthand fortifying to either proffer or guarantee its precious stone life isn't constrained. This paper plans to give the express a workmanship survey of different fortify and fix techniques for the RC section proposed by the variegated specialist over the Latest two decades. The adjustable of this survey paper is constrained to the jacketing strategy for fortifying and fixing the two normals and high quality RC sections. The paper in addition distinguishes potential research hole and layout the future course of investigation into the solid and fixes of RC sections.

Mansoor Ahmad Bhat \& Er. Gurpreet Singh (7), It is important to modify, repair, rehabilitation, or reconstruction of existing structures considering of various factors like yoke failure between and post joint, corrosion which leads to deterioration, natural disasters, etc. These factors result in cracking of our structures, i.e. the structures wilt unserviceable. Hence the modifications of these structure is required. This paper show an experiment study on RC beam retrofitted using unidirectional and bi-directional CFRP sheets. The mains objectives of the study is to investigation the policies of RC beam without retrofitting with CFRP sheets.

Kalpesh R. Kolhe, Manish D. Mata (8), Huge capital is put resources into development, arranging, and keeping up the nature of another structure. With time, old structures lose their quality and quality and in this way, they require limiting. Retrofitting helps in the limiting of olds structures by reestablishing their current highlights and improving their structure capacities. Legitimate towage of the harmed towers to execute retrofitting methods may help in reestablishing the quality and nature of old structures at lower relinquish and time. This paper, for the most part, focuses on the towage of harm working by utilizing variegated retrofitting strategies. Two variegated instances of retrofitting are introduced here. The examination, generally, centers around whether the all-out news structure is salubrious for the retrofitting of any current structures.

\section{CONCLUSION}

The related to what holds something together and makes it strong of a building helped and made by $\mathrm{RC}$ jacketing of the columns, like any other making stronger way of doing things, is highly effected by the following aspects: Repair method of the original column removing the common building material from the broken-down in bad form band, part by hand taking bits off, jack-hammering, electric hammering, or any other careful way that causes micro-cracking of the supporting structure is changed, should be had as ones trade by sand-blasting or water destruction ways of doing things. Interface surface preparation in the case of an undamaged and sound element, there is no need to improved the rough of the interface surfaces, except for the situation of short RC column, where sandblasting or water destruction should be used. Use of a gluing or joining together forming agent a two-part-related epoxy sticky, plastic like substance that usually comes from trees is most commonly used. Position of the steel bars of the related to studying things over a long time strengthening item/reward/supplies these should be completely spread. If this is not possible, attentions must be paids to avoid too many bundling at the corners. Added stirrups half of the spacing of the original crossing sideways strengthening 
item/reward/supplies is recommended for the added stirrups to get a like a huge stone behavior under cyclic loadings. These should also be placed out of phase. Added concrete a non-shrinkage concrete should be adopted with his or her usual of a selfcompacting, high-strength and high-ability to last concrete.

\section{REFERENCES}

[1]. Vijayakumar Amulya \& A. Dattatreya Kumar "Behaviour of RCC Column Strengthened using Steel Jacketing" International Journal for Research in Applied Science \& Engineering Technology (IJRASET) September 2017.

[2]. N. Lakshmanan, K. Muthumani \& T.S. Krishnamoorthy "Retrofitting Of Reinforced Concrete Structures Using Wrapping Technique" 4th International Conference on Earthquake Engineering, October 2006.

[3]. Prathamesh Dingorkar and Ayush Srivastava "Retrofitting - Comparative Study Of Rc Jacketing And Frp Wrapping" International Journal of Civil Engineering and Technology (IJCIET) September-October 2016.

[4]. Chetan Yalburgimath, Akash Rathod \& S Bhavanishankar " Retrofitting of Reinforced Concrete Beam Using Carbon Fiber Reinforced Polymer Fabric" International Research Journal of Engineering and Technology (IRJET) Oct 2007.

[5]. Tabish Rasool Sheikh, Mohd Kashif Khan, Tabish Izhar " A review on Strengthening of RCC square columns with Reinforced Concrete Jacketing" International Research Journal of Engineering and Technology (IRJET) March 2004.

[6]. Saim Raza , Muhammad K. I. Khan \& Scott J. Menegon "Strengthening and Repair of Reinforced Concrete Columns by Jacketing: State-of-the-Art Review" International
Research Journal of Engineering and Technology (IRJET) May -2015.

[7]. Mansoor Ahmad Bhat \& Er. Gurpreet Singh "Retrofitting of reinforced concrete Beams by using carbon fibre reinforced polymer sheets" International Journal of Civil Engineering and Technology (IJCIET) September 2012.

[8]. Kalpesh R. Kolhe, Manish D. Mata “Assessment of Damaged Building by Using Retrofitting Techniques- Case Study" International Journal of Engineering and Techniques - Volume 3 Issue 3, May-June 2017.

\section{Cite this article as :}

Uday Dongre, Dr. Kuldeep R. Dabhekar, Dr. Isha P. Khedikar, "A Review on Strengthening and Repair of RC Column by Jacketing", International Journal of Scientific Research in Science and Technology (IJSRST), Online ISSN : 2395-602X, Print ISSN : 23956011, Volume 7 Issue 3, pp. 113-117, May-June 2020. Available at doi : https://doi.org/10.32628/IJSRST1196511 Journal URL : http://ijsrst.com/IJSRST1196511 